\title{
YERE NÜFUZ EDEN RADAR YÖNTEMİ İLE BALAST KİRLİLİĞİIIN BELİRLENMESİ
}

\section{Mehmet Çağrı BAYRAK $^{1 *}$, Mesut TIĞDEMíR ${ }^{2}$, Mustafa KARAŞAHİN ${ }^{3}$, Olcay ÇAKMAK $^{1}$}

${ }^{1}$ Süleyman Demirel Üniversitesi, Deprem ve Jeoteknik Araştırma Merkezi, Isparta, Türkiye

${ }^{2}$ Süleyman Demirel Üniversitesi, Mühendislik Fakültesi, İnșaat Mühendisliği Bölümü, Isparta, Türkiye

3 İstanbul Gelişim Üniversitesi, Mühendislik ve Mimarlık Fakültesi, İnşaat Mühendisliği Bölümü, İstanbul, Türkiye

\begin{tabular}{ll}
\hline Anahtar Kelimeler & Öz \\
\hline Balast Kirliliği, & Bu çalışmada, demiryolu altyapısındaki kirlenmeye bağlı kusurları yere nüfuz eden \\
GPR, & radar (GPR) kullanarak tespit etmek amacıyla İstanbul-Edirne demiryolu hattının \\
Demiryolu, & Çatalca bölgesinde çalışmalar yürütülmüştür. Yenilenen demiryolu hattında \\
Demiryolu Altyapısı. & yenileme çalışmalarından önce ve sonra ölçümler yapılmıștır. Ayrıca balast \\
& numunesi alınarak kirlilik derecesi belirlenmiştir. Yapılan değerlendirmeye göre \\
& eski demiryolunda balast tabakasının aşırı deformasyonu, balast cepleri ve balast \\
& kirliliği tespit edilmiştir. Yenileme sonrasında altyapı tabakaları tespit edilmiştir. \\
& Eski ve yeni demiryolu hattında yapılan radar ölçüm sonuçları karşlaştırmalı olarak \\
& sunulmuştur. \\
\hline
\end{tabular}

\section{DETERMINATION OF BALLAST FOULING VIA GROUND PENETRATING RADAR}

Keywords
Ballast Fouling,
GPR,
Railway,
Railway Infrastructure.

\begin{abstract}
In this study, investigations are carried out in the Çatalca region of the IstanbulEdirne railway line in order to detect defects related to the contamination in the railway infrastructure using ground penetration radar. Measurements are performed before and after the renovation works on the renewed railway line. In addition, the ballast sample is taken, and the degree of fouling is determined. According to the evaluation, excessive deformation of the ballast layer, ballast pockets and ballast fouling are detected in the old railway. Infrastructure layers are determined after the renovation. The radar measurement results on the old and new rail lines are presented comparatively.
\end{abstract}

\section{Alıntı / Cite}

Bayrak, M.Ç., Tığdemir, M., Karaşahin, M., Çakmak, O., (2020). Yere Nüfuz Eden Radar Yöntemi ile Balast Kirliliğinin Belirlenmesi, Mühendislik Bilimleri ve Tasarım Dergisi, 8(2), 572-581.

Yazar Kimliği / Author ID (ORCID Num
M.Ç Bayrak, 0000-0002-9995-7325
M. Tığdemir, 0000-0002-5303-2722
M. Karaşahin, 0000-0002-3811-2230
O. Çakmak, 0000-0003-4282-4481
Makale Süreci / Article Process Başvuru Tarihi / Submission Date $\quad 27.02 .2020$ Revizyon Tarihi / Revision Date 13.04 .2020 Kabul Tarihi / Accepted Date $\quad 29.04 .2020$ Yayım Tarihi / Published Date $\quad$ 25.06.2020

\section{Giriş (Introduction)}

Gelişen ülkelerde demiryolları hem yolcu taşımacılığında hem de yük taşımacılığında ekonomiye katkı sağlamaktadır. Demiryolu taşımacılığının artması karşılaşılan sorunları da beraberinde getirmektedir. Dolayısıyla yüksek yatırım maliyetleriyle yapılan demiryollarındaki kusurların erken tespiti, bakım çalışmalarının zamanında yapılması için önemlidir.

Ülkemizde demiryolları üstyapısı genellikle balastlı tipte yapılmaktadır. Dinamik tren yüklerinin etkisi altındaki demiryolu altyapısında başta balast kirliliği olmak üzere zamanla bozulmalar meydana gelmektedir. Balast daneleri arasına giren ince malzemelerin balast tabakasının boşluklarını doldurmasına balast kirlenmesi denilmektedir, böylece kirlenen balast tabakası fonksiyonlarını yerine getiremez. Demiryollarının ekonomik ve stratejik öneminden dolayı karşılaşılan sorunların irdelenmesi ulaştırma mühendisliği için özel bir öneme sahiptir. $\mathrm{Bu}$ nedenle, demiryollarında karşılaşılan bozulmalar ile ilgili çok sayıda araştırma yapılmıştır. Selig ve Waters

\footnotetext{
* ilgili yazar / Corresponding author: mcbayrak@yahoo.com, +90-246-211-1600
} 
(1994) demiryolu bozulması olarak balast kirliliği kavramını tanımlamış ve balast tabakasını kirlenme derecesine göre sınıflandırmıştır. Indraratna vd. (2011) balast kirliliğinin sınıflandırılması ve değerlendirilmesi için yeni bir parametre önermiştir. Huang ve Tutumluer (2011) kirlenmenin balast mukavemeti ve stabilitesi üzerindeki etkisini belirlemiştir. Indraratna vd. (2014) doğrudan kesme deneyi uyguladığı temiz ve kömür tozu ile kirlenmiş numuneleri ayrık eleman yöntemi ile modellemiş ve elde ettiği analiz sonuçları ile karşılaştırmıştır. Ebrahimi vd. (2014) balast tabakasını kirletici malzemenin kohezyonsuz ve kohezyonlu olmasına göre iki farklı kirlenme indeksi önermiştir. Esmaeili vd. (2014) kumla kirlenmiş balastın tren yüklerinden kaynaklanan titreşim üzerindeki etkisini deneysel ve sayısal yöntemlerle araştırarak balast kirlenmesini ivme ve yerdeğiştirme ile ilişkilendirmiştir. Parsons vd. (2014) balast kirlenmesi ile geçirgenliği arasındaki ilişkiyi rezistivite yöntemi kullanarak incelemiştir. Danesh vd. (2018) balast kirliliğinin derecesinin kayma mukavemeti üzerindeki etkisini araştırmıştır. Kashani vd. (2018) yaptığı üç eksenli testler ile kirlenmenin ve kirlenmeye bağlı olarak tutulan su içeriğinin balast tabakasının mukavemet ve bozulma özellikleri üzerindeki etkisini incelemiştir.

Balast kirliliğinin demiryolu altyapısı bakımından önemli bir problem olması nedeniyle literatürde oldukça yoğun çalışma alanına sahiptir. Pratik olmasından dolayı tercih edilen GPR ile yapılan çalışmalar çoğunluktadır. Olhoeft ve Selig (2002) balast ve altbalast tabakalarının kalınlığını, yol boyunca tabaka kalınlıklarındaki değişimleri, balast içindeki su ceplerini ve yüksek su muhtevasına sahip taban zemini gibi demiryolu altyapısının özelliklerini gözlemlemişlerdir. Al-Qadi vd. (2010) demiryolu altyapı değerlendirmesi için çoklu frekansa sahip yer radarı sisteminde, radar analiz sonuçlarını balast gradasyon deneyleri ve gözlem çukuru ile birlikte doğrulayarak anten optimizasyonu yapmıștır. Shao vd. (2011) balast koşullarını değerlendirmek için otomatik bir sınıflandırma sistemi sunmuştur. Anbazhagan vd. (2011) tahribatsız testler olarak sismik yüzey dalgası ve GPR yöntemlerini kullanarak balast kirlenme derecesinin ve kirlenme türlerini belirlemiştir. Fontul vd. (2016) bozulma nedenlerini tespit etmek amacıyla Portekiz demiryolu ağında radar ölçümlerine dayalı vaka çalışması gerçekleștirmiştir. Benedetto vd. (2017) çalışmasında demiryolu balast koşullarının değerlendirilmesi ve izlenebilmesi için yeni ve etkili bir sinyal işleme yöntemi önermiştir. Tosti vd. (2018) düşükten yükseğe kadar farklı frekanslardaki radar antenlerini kullanarak laboratuvar ortamında balast kirliliğinin dielektrik geçirgenliğine ilişkin bir çalışma yapmıştır. Yurlov vd. (2019) Radar parametreleriyle geometrik bozulmaların oranları arasındaki istatistiksel ilişkiyi incelemiş, ayrıca radar parametrelerine bağlı olarak bir tahmin modeli geliştirmiştir.

Bu çalışmada, demiryolu altyapısındaki kirlenmeye bağlı kusurları GPR kullanarak tespit etmek amacıyla İstanbulEdirne demiryolu hattının Çatalca bölgesinde çalışmalar yürütülmüştür. Yenilenen demiryolu hattında yenileme çalışmalarından önce ve sonra olmak üzere aynı yerde ölçümler yapılmıştır. Ayrıca balast numunesi alınarak kirlilik derecesi belirlenmiştir. Yapılan değerlendirmeye göre eski demiryolunda balast tabakasının aşırı deformasyonu, balast cepleri ve balast kirliliği tespit edilmiştir. Yenileme sonrasında altyapı tabakaları tespit edilmiştir. Eski ve yeni demiryolu hattında yapılan radar ölçüm sonuçları karşılaştırmalı olarak sunulmuştur. Bir demiryolunun olabilecek en kötü ve en iyi durumu görüntülenmiştir.

\section{Materyal ve Yöntem (Material and Method)}

\subsection{Balast Kirliliği (Ballast Fouling)}

Şekil 1'de görüldüğü gibi balastlı tipteki bir demiryolunda, raylar, traversler ve bağlantı elemanları üstyapıyı oluştururken, balast, altbalast ve taban zemini altyapıyı oluşturur (Al-Qadi vd., 2008). Ayrıca taban zemininin durumuna göre altbalast tabakasının altına takviye tabakaları da ilave edilebilir. Ray-travers birleşiminden aktarılan gerilmeleri ilk olarak karşılayan balast tabakası altyapının en önemli elemanıdır.

Sert taşlar ve kayaçlardan imal edilen balast tabakası, esnekliği sayesinde dinamik kuvvetleri sönümleyerek, altyapı tabakalarına iletilen gerilmeleri azaltabilmeli ve yeterli drenajı sağlayabilmelidir. Bununla birlikte, balast tabakasında zamanla bozulmalar meydana gelir.

Balast kirlenmesi sonucunda drenaj özelliğini kaybeden altyapıda bozulmalar ve plastik deformasyonlar meydana gelmektedir. Kirlenme seviyesine ve uygulanan tekrarlı yüklere bağlı olarak ilerleyen aşırı deformasyonların sonucunda balast cepleri meydana gelmektedir. Şekil 2'de tipik bir balast cebinin şekli yer almaktadır (Li vd. 2016). 


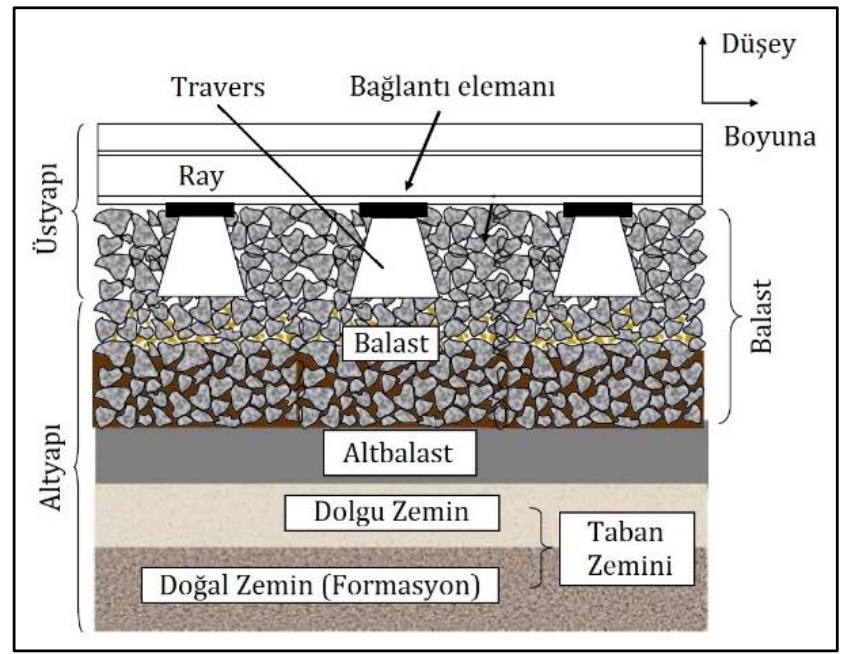

Şekil 1. Demiryolu yapısı (Railway structure)

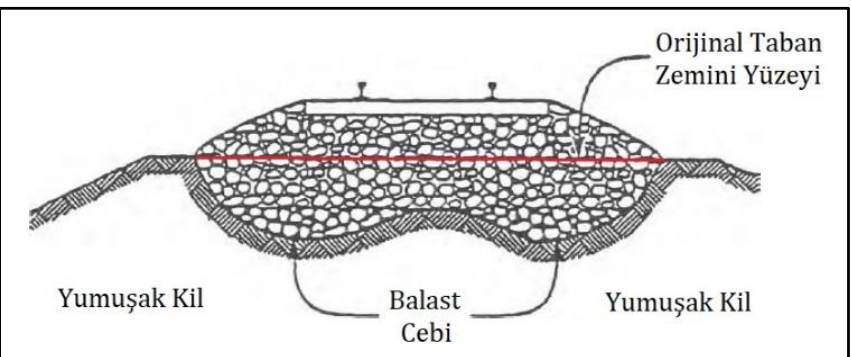

Şekil 2. Taban zemininin aşırı plastik deformasyonu - balast cebi (Excesive plastic deformation of subgrade - ballast pocket)

Selig ve Waters, (1994) çalışmalarında, balast kirliliğini deneysel olarak belirlemek için kirli ve temiz balasttan 15 kg'dan az olmayacak şekilde numuneler almışlar ve balast kirliliğini gösteren kirlilik indeksini $(F I)$, aşağıdaki şekilde hesaplamışlardır;

$$
F I=P 4+P 200
$$

Burada, $P 4 ; 4$ nolu elekten geçen yüzde ve $P 200 ; 200$ nolu elekten geçen yüzde değeridir.

Hesaplanan kirlenme indeksine göre Tablo 1'deki sınıflandırmaya göre balast tabakasının kirlenme derecesi tespit edilmektedir.

Tablo 1. Kirlenme kriteri (Fouling criteria)

\begin{tabular}{|c|c|}
\hline Kategori & Kirlenme indeksi \\
\hline Temiz & $<1$ \\
\hline Kısmen temiz & $1-9$ \\
\hline Kısmen kirli & $10-19$ \\
\hline Kirli & $20-39$ \\
\hline Çok kirli & $>39$ \\
\hline
\end{tabular}

\subsection{GPR Çalışması (GPR Study)}

GPR kullanılarak demiryolunun altyapı tabakalarının durumları ve balast kirliliği belirlenmektedir. Radarın yaydığı elektromanyetik dalgalar altyapı tabakalarından yansımakta ve altyapı tabakalarının durumunun belirlenmesini sağlamaktadır. Homojen ve izotropik malzemeler için radar dalgasının rölatif yayılma hızına bağlı olarak aşağıdaki eşitliklerden hesaplanmaktadır (Daniels, 2004);

$$
v_{r}=\frac{c}{\sqrt{\varepsilon_{r}}}
$$




$$
d=v_{r} \frac{t}{2}
$$

Burada, $v_{r}$; rölatif yayılma hızı $(\mathrm{m} / \mathrm{s}), c$; ışık hızı $\left(3 \times 10^{8} \mathrm{~m} / \mathrm{s}\right), \varepsilon_{r}$; dielektrik sabiti, $d$; tabaka kalınlığı (m), $t$; radar sinyalinin gidiş-geliş süresi $(\mathrm{s})$.

İstanbul-Çatalca bölgesinde yer alan demiryolunun yenilenmesi çalışmaları sırasında GPR ölçümleri yapılmıştır. Yenileme çalışmaları başlamadan önce GPR ölçümleri yapılmış ve eski yol kaldırılıp yenisi yapıldıktan sonra ölçümler tekrarlanmıştır. Bu sayede bir demiryolunun en kötü durumu ve aynı zamanda en iyi durumu tespit edilmiştir.

Ölçümlerde IDS marka $600 \mathrm{MHz}$ ve $1600 \mathrm{MHz}$ frekanslarda eş zamanlı ölçüm yapan çift antenli bir radar cihazı kullanılmıștır. Balast tabakasının görüntülenmesinde genellikle yüksek frekanslı antenler kullanılmasına rağmen, yüksek frekanslı antenler altyapı tabakalarını görüntülemek için yeterli gelmemektedir. İncelenen demiryolunda toplam kalınlığı 2 m'yi geçen altyapı tabakalarını görüntülemek için daha derine nüfuz eden $600 \mathrm{MHz}$ antenden elde edilen veriler değerlendirilmiştir. Ölçümler raylarda giden 4 tekerlekli bir GPR taşıyıcı kullanılarak yapılmıştır (Şekil 3).

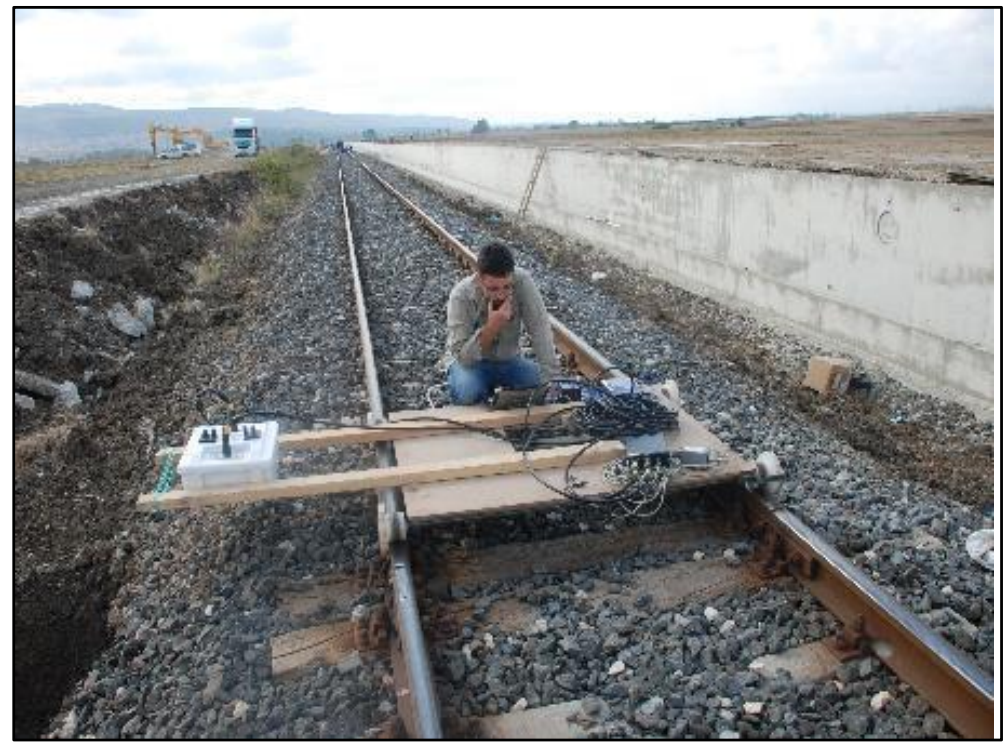

Şekil 3. Demiryolu GPR uygulaması (Railway GPR application)

GPR ile hattın ortasından yapılan ilk deneme ölçümlerinde beton traverslerin radar sinyallerini yansıttığı ve bunun sonucunda görüntünün netliğinin oldukça azaldığı belirlenmiştir. Radar sinyallerinin beton traverslerden yansıyarak saçılmasını önlemek için traverslerin $5 \mathrm{~cm}$ kadar dışından da ölçüm yapılarak radar sinyallerinin doğrudan demiryolunun alt tabakalarına iletilmesi sağlanmıştır.

Çalışmalarda kullanılan radar anteni bir tane olduğu için hattın ortasından, solundan ve sağından yapılan ölçümler başlangıcı ve bitişi işaretlenen kesimde tekrarlanarak yapılmıștır (Şekil 4). Yenileme çalışmalarından sonra yapılan ölçümler hattın ortasından ve solundan yapılmıştır. Yenileme sonrası yapılan ölçümler sırasında incelenen demiryolunun altyapısında henüz bozulma olmadığı için tek taraftan yapılan ölçüm yeterli görülmüştür. Verilerin değerlendirilmesi aşamasında Reflexw programı kullanılmıştır. Uygulanan filtreleme işlemleri sonucunda sinyal kaydındaki (radargram) gürültüler azaltılmış, altyapı tabakalarının ara yüzeyinden yansıyan sinyallerin genlikleri artırılmış ve tabaka sınırları daha belirgin hale getirilmiştir.

Yenileme sonrası demiryolu hattının toplamda $2.20 \mathrm{~m}$ derinliğe ulaşan altyapı tabakalarının tasarım ve uygulama kalınlıkları aşağıda yer almaktadır.

- Balast $0.30 \mathrm{~m}$,

- Altbalast $0.20 \mathrm{~m}$,

- Alttemel $0.40 \mathrm{~m}$,

- Dolgu: $0.60 \mathrm{~m}$

- Kaya dolgu 0.70 m'dir. 


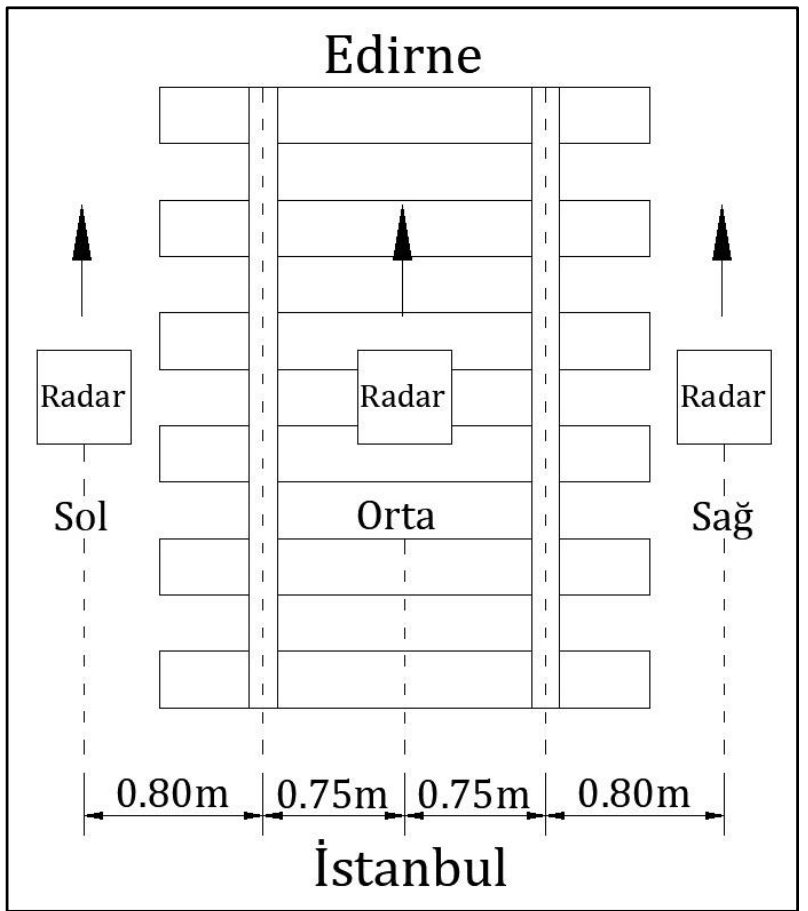

Şekil 4. Radar ölçüm konumu ve yönü (Radar measurement position and direction)

\section{Deneysel Sonuçlar (Experimental Results)}

\subsection{Balast Kirliliği Sonuçları (Ballast Fouling Results)}

Kirli balast malzemesi incelendiğinde içerisinde bazalt, kireç taşı ve nehir taşı malzemelerine rastlanmıştır. Şekil 5 'te kirli balast daneleri yeni balast daneleri ile birlikte görülmektedir.

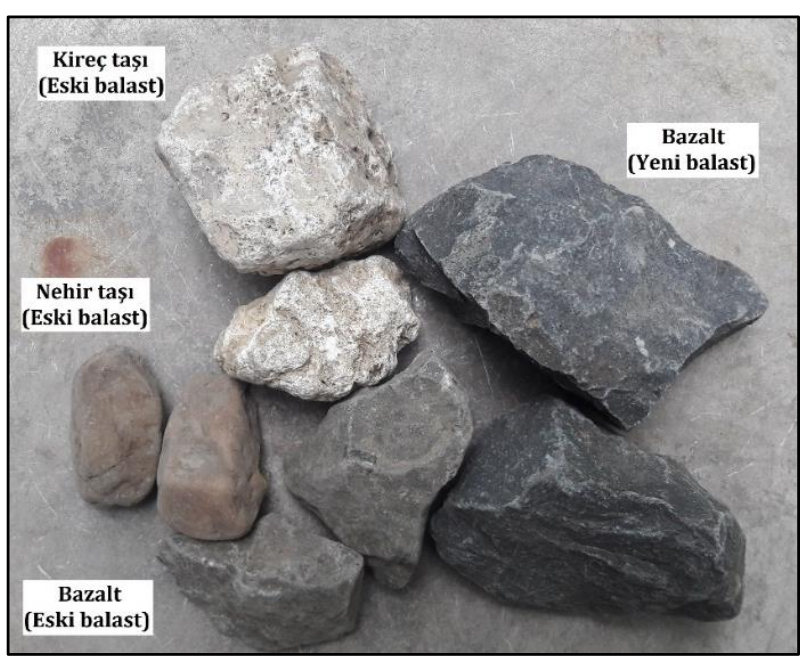

Şekil 5. Balast daneleri (Ballast particles)

Eski demiryolu kaldırılırken alınan kirli balast numuneleri üzerinde kirlenme analizleri yapılmıştır. Eleme işlemi yaklaşık 15 kg'lık kirli balast numunesi üzerinde yapılmıştır. Kirli balastın içerisinde bulunan yeni balast danelerinin boyutlarını belirlemek için numuneler ilk olarak balast eleklerinden elenmiştir. Balast eleklerinden elendikten sonra en küçüğü 200 nolu elek olmak üzere balast eleklerinden daha küçük çaplı elekler kullanılmıştır. 4 nolu ve 200 nolu eleklerden geçen malzeme miktarı hesaplanarak Tablo 1'deki kriterlere göre kirlenme seviyesi belirlenmiştir. Eleme işlemi uygulanan malzeme Şekil 6’da yer almaktadır.

Şekil 7'de yenileme öncesi alınan kirli balast numunesinin yenileme sonrası alınan temiz balast numunesi ile karşılaştırılması yer almaktadır. İçinde ince malzeme bulunmayan açık gradasyona sahip temiz balast daneleri dinamik yüklerin etkisi altında zamanla kırılarak ufalanmaktadır. Balast kırılması ve çevreden taşınan ince malzemelerin etkisiyle temiz balast kirli balast haline dönüşmektedir. Kirlenmeye bağlı olarak gradasyon eğrisi sola doğru kaymaktadır. 


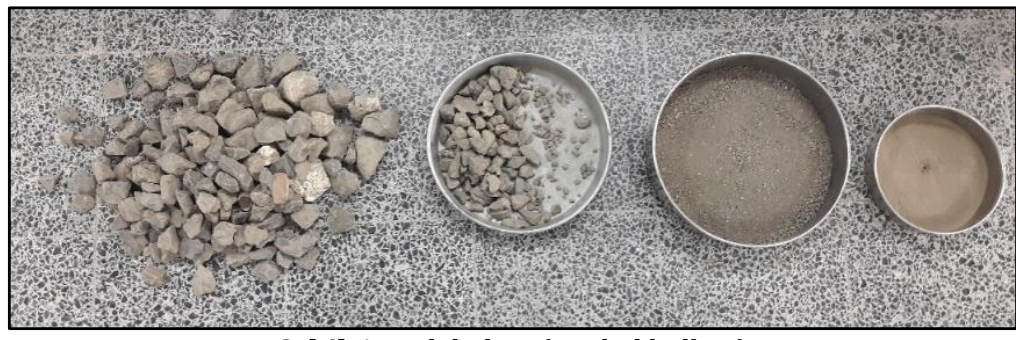

Şekil 6. Kirli balast (Fouled ballast)

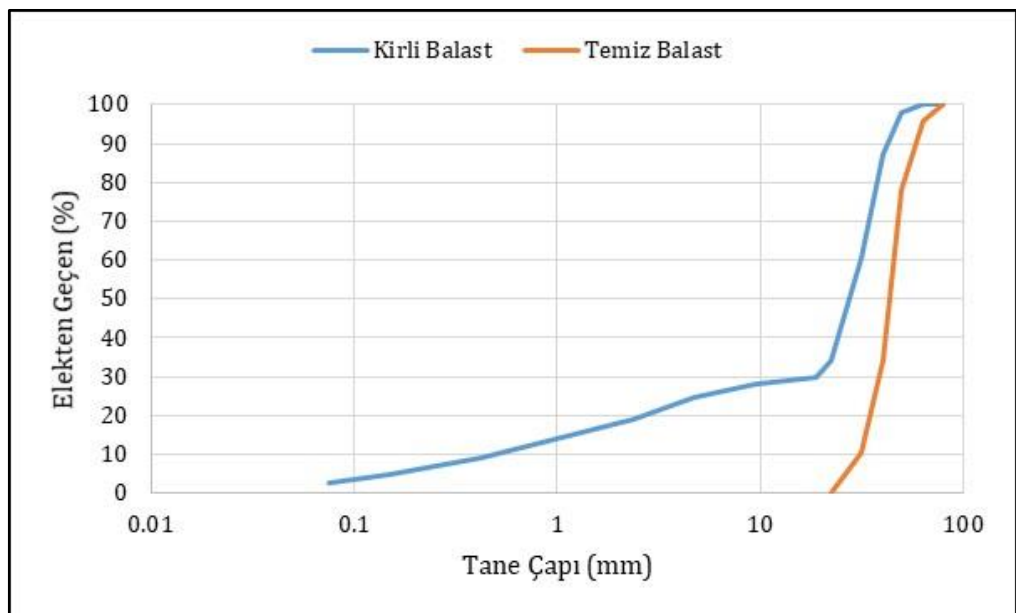

Şekil 7. Kirli ve temiz balast gradasyonu (Fouled and clean ballast gradation)

\subsection{GPR Sonuçları (GPR Results)}

İncelenen eski demiryolu kesiminde balast tabakasının durumunu belirlemek için kirlenme analizi yapılmıştır. Şekil 8'de yenileme çalışmaları sırasında tespit edilen eski demiryolunun kesiti yer almaktadır. Demiryolu kesitinde karakteristik aşırı deformasyondan kaynaklanan balast cebi görülmektedir.

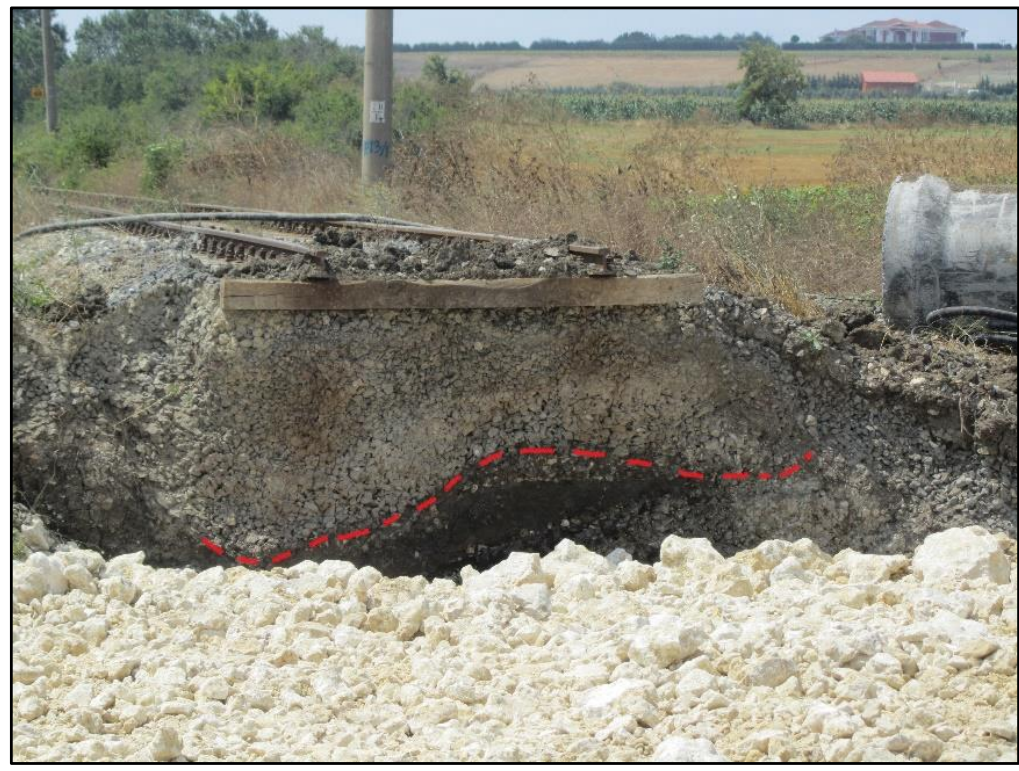

Şekil 8. Eski demiryolu hattı kesitinde balast cebi (Ballast pocket in old railway line cross section)

Radar verilerinin değerlendirilmesinde, radar ile balast tabakası arasındaki hava bölgesinin kesilip atılmasından sonra olası tabaka sınırları işaretlenmiştir. Eski yoldaki ölçümler Şekil 8'de yer alan kesit üzerinden, yeni yolda yapılan ölçümler tasarım ve uygulama kalınlıkları ile karșılaștırılarak kontrol edilmiștir. Yenileme öncesi ve sonrası hattın ortasından yapılan ölçümlerde traverslerin radar sinyallerini yansıtmasından dolayı anlaşılır bir görüntü elde edilememiştir (Şekil 9). Tabaka sınırlarını andıran çizgiler yer almasına rağmen altyapı tabaka kalınlıkları ile tutarlılık gözlenememiştir. Dolayısıyla tabaka sınırı gibi görülen çizgilerin yansımadan kaynaklandığı düşünülmüştür. 

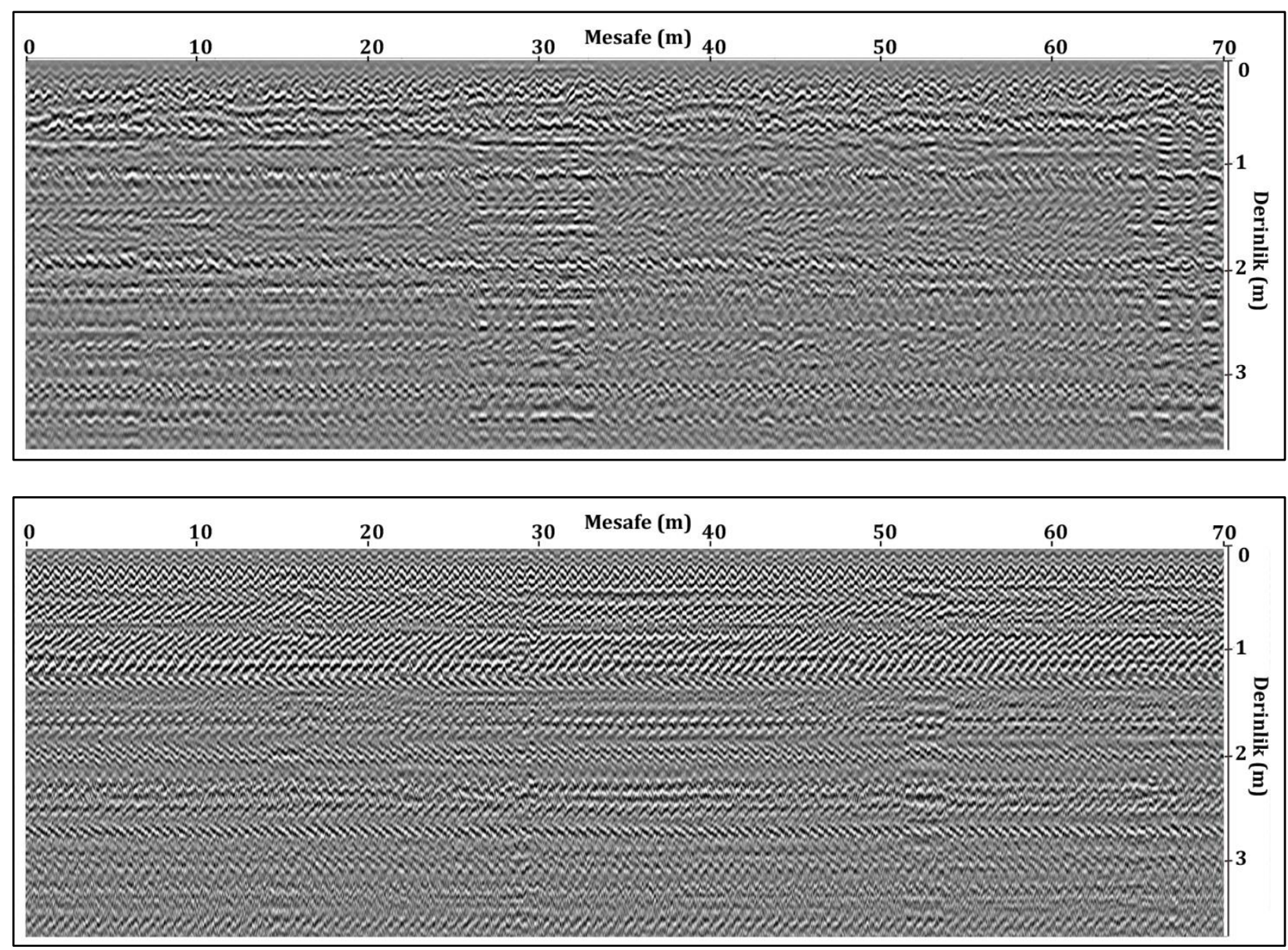

Şekil 9. Eski ve yeni yolda hattın ortasından yapılan ölçümlerdeki aşırı yansımalar (Excessive reflections from the center of the line on the old and new railway)

Eski yolda hattın solundan yapılan ölçüm Şekil 10'da yer almaktadır. Yeşil kesikli çizgi ile işaretlenen bölgenin detaylı değerlendirmesi Şekil 11'de gösterilmiştir. Aynı şekilde eski yolda hattın sağından yapılan ölçüm Şekil 12'de, yeşil kesikli çizgilerle işaretlenen bölgenin detaylı değerlendirmesi Şekil 13'te gösterilmiştir.

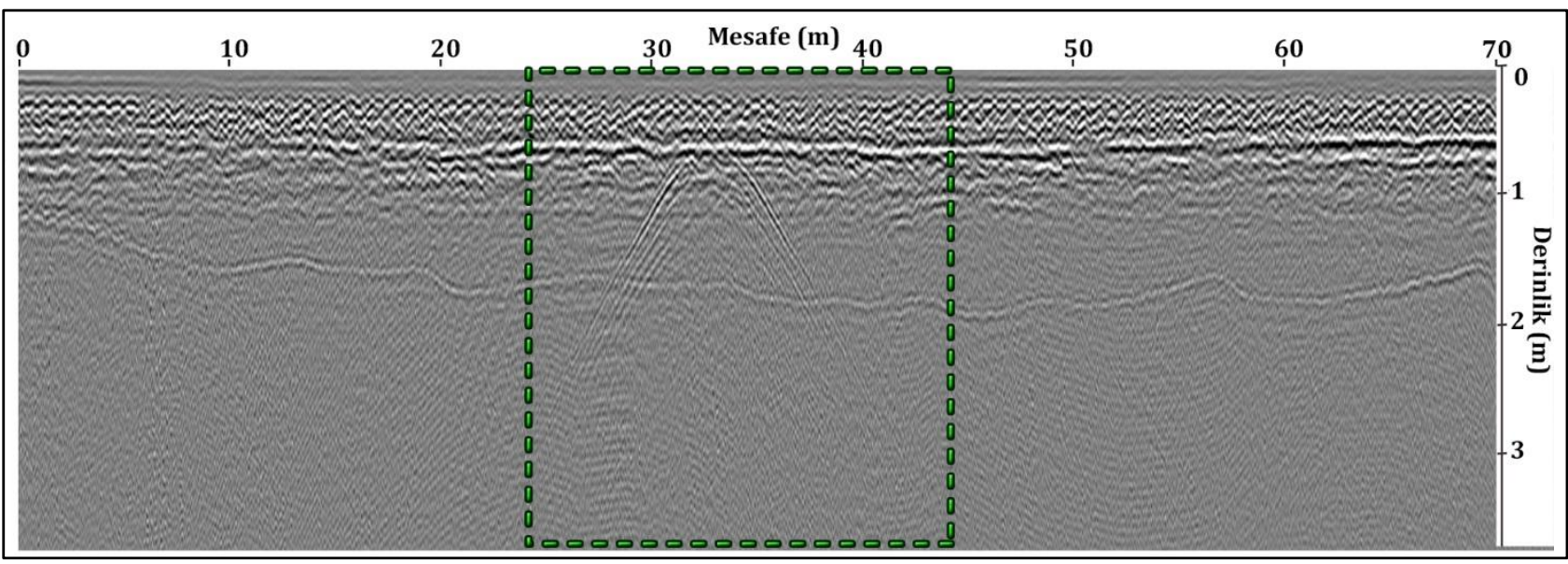

Şekil 10. Eski yolda hattın solundan yapılan ölçüm (Measurement from the left of the line on the old railway)

Demiryolu altyapısı $0.3 \mathrm{~m}$ balast ve $0.2 \mathrm{~m}$ altbalast olmak üzere $0.5 \mathrm{~m}$ den oluşmaktadır. Şekil 11 'de eski yolda hattın solundan yapılan ölçüm detayında balast tabakası yaklaşık $1.5 \mathrm{~m}$ kalınlığa ulaştığı görülmektedir. Benzer şekilde, Şekil 13'te eski yolda hattın sağından yapılan ölçüm detayında balast tabakası yaklaşık $1.2 \mathrm{~m}$ kalınlığa ulaştığı görülmektedir. Şekil 8'de yer alan eski demiryolu kesiti incelendiğinde sonuçların radar verileri ile uyumlu olduğu anlaşılmaktadır. 


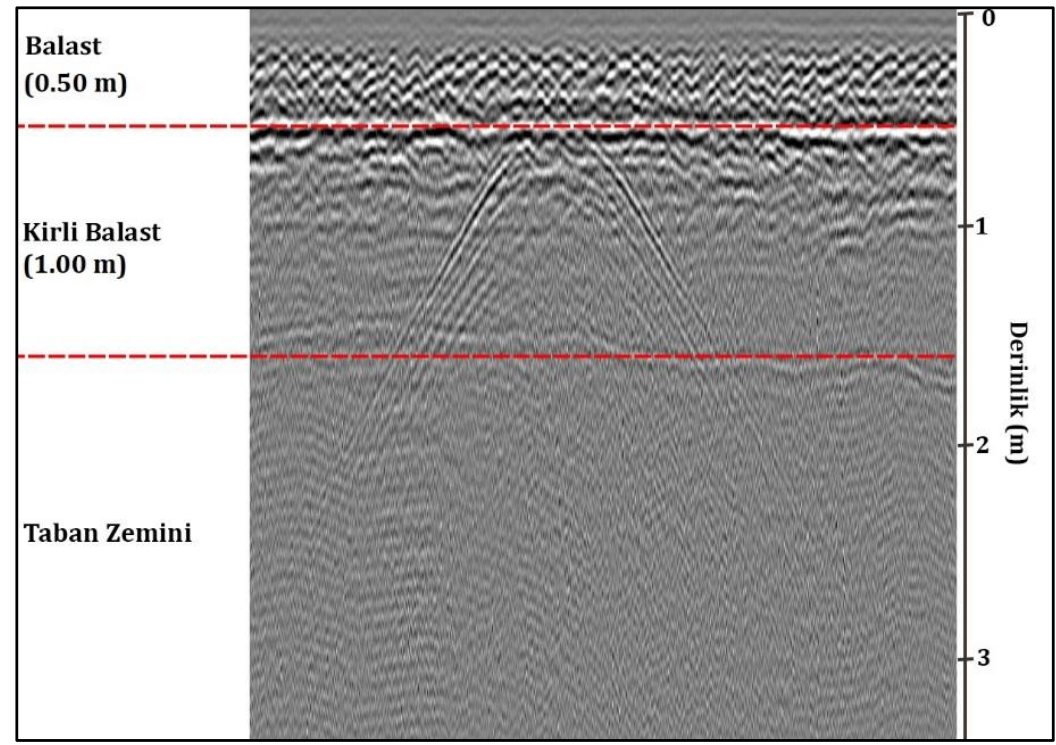

Şekil 11. Eski yolda hattın solundan yapılan ölçüm detayı (Measurement detail from the left of the line on the old railway)

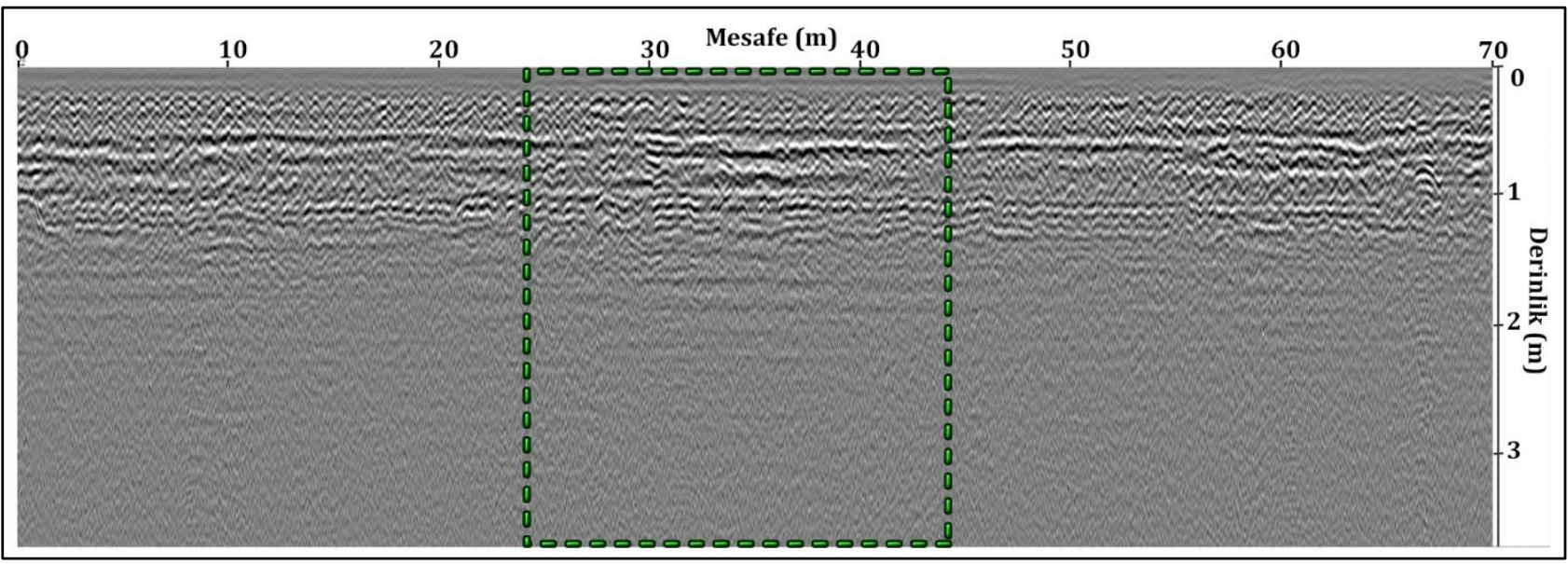

Şekil 12. Eski yolda hattın sağından yapılan ölçüm (Measurement to the right of the line on the old railway)

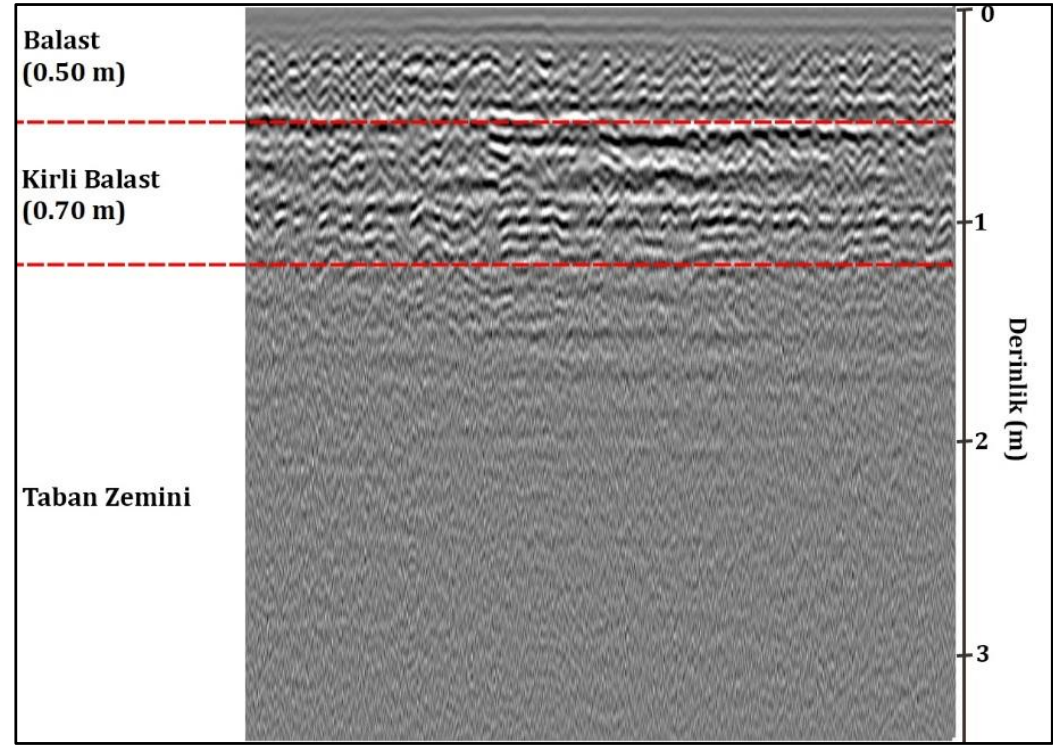

Şekil 13. Eski yolda hattın sağından yapılan ölçüm detayı (Measurement detail to the right of the line on the old railway)

Şekil 11 ve Şekil 13'te yer alan eski yolun solunda ve sağında yapılan ölçümlerin detaylı değerlendirmesi incelendiğinde, yüzeyden itibaren ilk 0.50 m derinliğe kadar nispeten daha temiz balast malzemesi yer almaktadır. Kirlenmeye neden olan ince malzemenin balast boşluklarından aşağıya inmesi sonucunda balast tabakasının alt kısımlarındaki boșlukları doldurmaktadır. 
Yeni yolda hattın solundan yapılan ölçüm Şekil 14'te, yeşil kesikli çizgi ile belirtilen bölgenin detaylı değerlendirmesi Şekil 15'de gösterilmiştir.

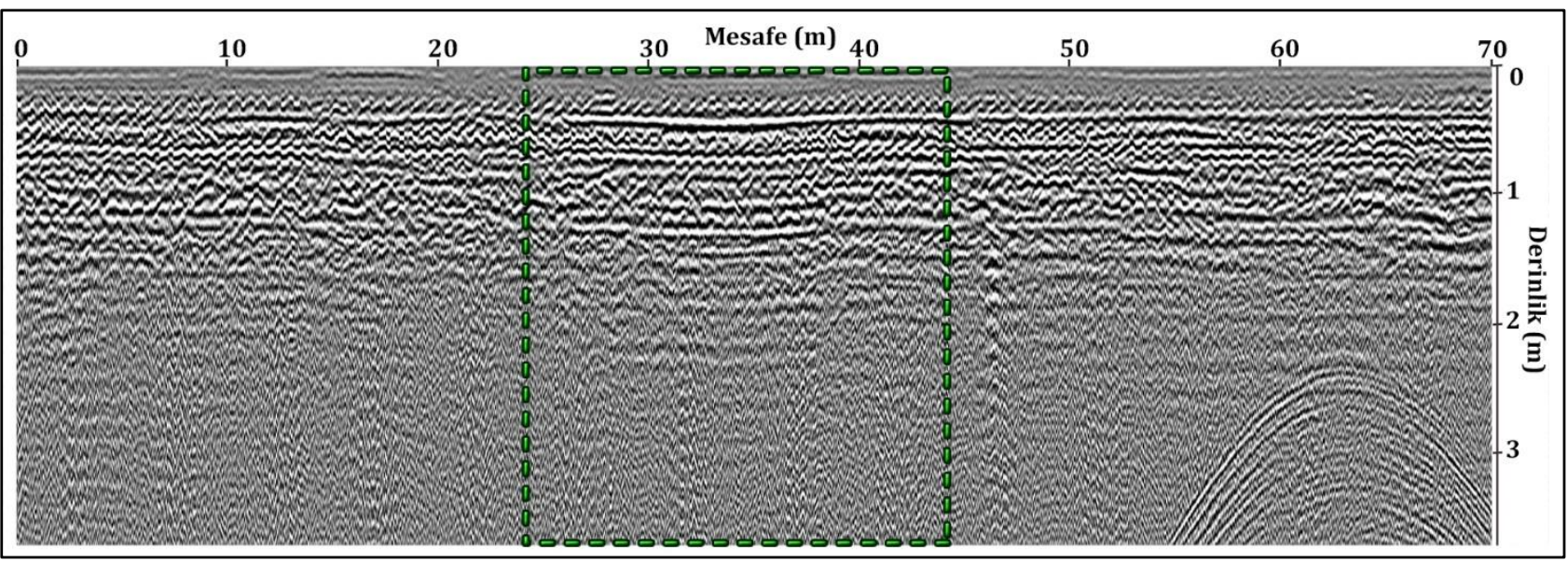

Şekil 14. Yeni yolda hattın solundan yapılan ölçüm (Measurement on the left of the line on the new railway)

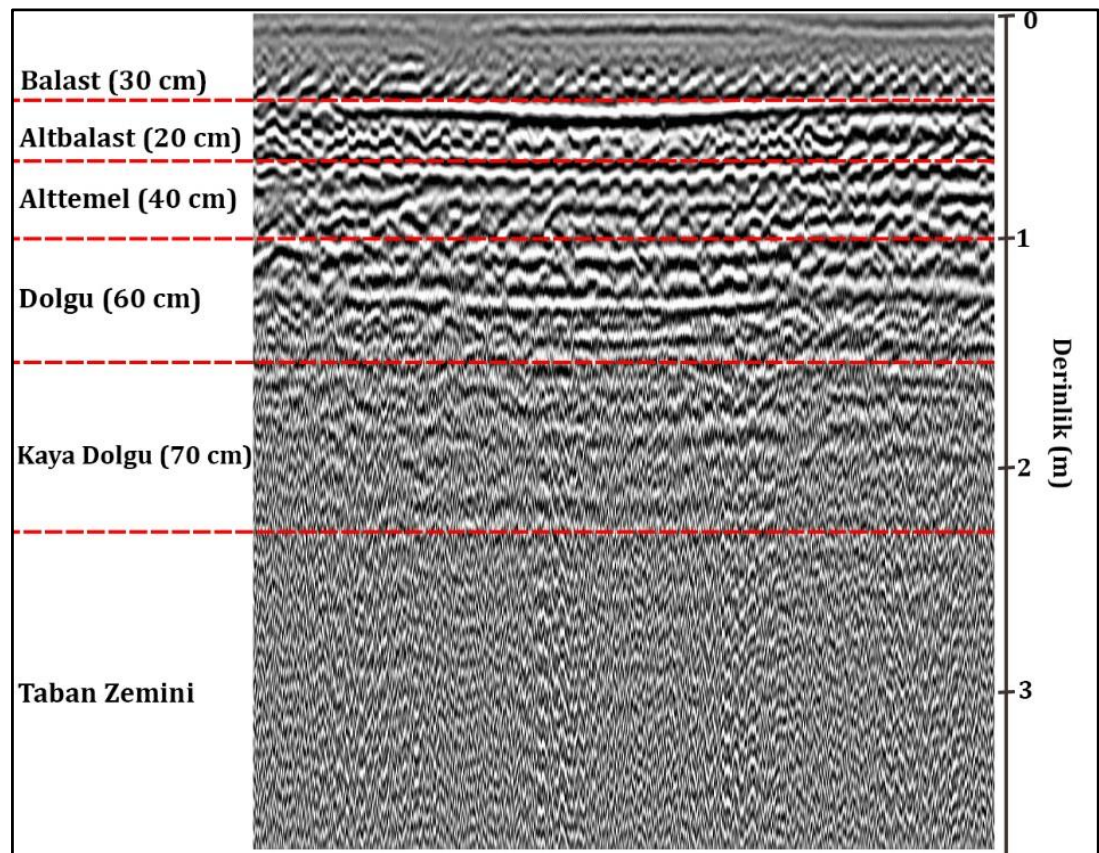

Şekil 15. Yeni yolda hattın solundan yapılan ölçüm detayı (Measurement detail on the left of the line on the new railway)

Yeni yolda yapılan ölçümün detayı (Şekil 15) incelendiğinde birim hacim ağırlıkları birbirinden farklı altyapı elemanları görülmektedir. Sürekli siyah-beyaz çizgiler tabakalar arasındaki ara yüzeyleri temsil etmektedir. Olması gerekenden daha fazla çizgi görülmektedir. Örneğin dolgu tabakası iki tabakadan oluşmuş gibi görünen dolgu tabakası iki aşamada serilip sıkıştırılmış tek bir tabakadır. Radar verilerinde altyapının toplam kalınlı̆̆ı olan 2.20 m'den daha derinde demiryolu yapısına rastlanmamıștır.

\section{Sonuç ve Tartışma (Result and Discussion)}

İstanbul - Edirne demiryolu hattının Çatalca ilçesindeki yenileme çalışmaları sırasında yürütülen çalışmada demiryolunun eski ve yeni durumu GPR ölçümleri yapılarak belirlenmiştir. Yenileme çalışmalarından önce yapılan ölçüm yolun en kötü durumunu, yenileme çalışmalarından sonra yapılan ölçüm ise yolun en iyi durumunu temsil etmektedir. İncelenen ölçüm kesiminden alınan balast numunesi üzerinde yapılan elek analizleri ile eski balastın kirlenme seviyesi belirlenmiştir.

- Yapılan inceleme sonucunda, yenileme sonrasında yeni yapılan yolun bilinen altyapı tabakalarının kalınlıkları radar ölçümleri ile karşılaştırılmıştır. Ölçümlerden elde edilen tabaka kalınlıklarının altyapı tabaka kalınlıkları ile uyumlu olduğu tespit edilmiştir. 
- Radar verilerinde yeni yolun daha fazla tabakadan oluştuğu görülmektedir. Bu durumun altyapı tabakalarının tek seferde değil birkaç seferde sıkıştırılmasından kaynaklanan ara yüzeylerden oluştuğu belirlenmiştir.

- Yenileme öncesi eski yolda yapılan radar ölçümlerine bakıldığında aşırı deformasyonlardan kaynaklanan balast tabakasının kalınlığındaki değişimler ve balast cepleri belirlenmiștir.

Eski hat balast tabakasında kirlenme seviyesi indisi (FI) \%28 olarak bulunmuștur.

- $\quad$ Radar ölçümlerinde eski balast tabakasının 2 tabakadan oluştuğu görülmektedir. Eski balast tabakasının deformasyonu sonucunda yolu eski kotuna getirmek için eklenen yeni balastın üstte olması ile ufalanan ve kirlenen balastın altta kalmasından kaynaklandığı düşünülmektedir.

\section{Teşekkür (Acknowledgement)}

Bu çalışma Süleyman Demirel Üniversitesi Bilimsel Araştırma Projeleri Koordinasyon Birimi tarafından 3165-D112 nolu proje kapsamında desteklenmiștir.

\section{Çıkar Çatışması (Conflict of Interest)}

Yazarlar tarafından herhangi bir çıkar çatışması beyan edilmemiştir. No conflict of interest was declared by the authors.

\section{Kaynaklar (References)}

Al-Qadi, I., Xie, W., Roberts, R., 2008. Time-Frequency Approach for Ground Penetrating Radar Data Analysis to Assess Railroad Ballast Condition. Research in Nondestructive Evaluation, 19:4, 219-237.

Al-Qadi, I., Xie, W., Roberts, R., 2010. Optimization of Antenna Configuration in Multiple-Frequency Ground Penetrating Radar System for Railroad Substructure Assesment. NDT\&E International, 43, 20-28.

Anbazhagan, P., Su, L., Indraratna, B., Rujikiatkamjorn, C., 2011. Model Track Studies on Fouled Ballast Using Ground Penetrating Radar and Multichannel Analysis of Surface Wave. Journal of Applied Geophysics. 74, 175-184.

Benedetto, F., Tosti, F., Alani, M., 2017. An Entropy-Based Analysis of GPR Data for the Assessment of Railway Ballast Conditions. IEEE Transactions on Geoscience and Remote Sensing. Vol.55, No.7.

Danesh, A., Palassi M., Mirghasemi A.A., 2018. Effect of Sand and Clay Fouling on the Shear Strength of Railway Ballast for Different Ballast Gradations. Granular Matter (2018) 20: 51.

Daniels, D.J. (Ed), 2004. Ground Penetrating Radar - 2nd Edition. The Institution of Electrical Engineers, London, United Kingdom.

Ebrahimi, A., Tinjum, J.M., Edil, T.B., 2014. Deformational Behavior of Fouled Railway Ballast. Canadian Geotechnical Journal. $52,344-355$

Esmaeili, M., Zakeri, J.A., Mosayebi, S.A., 2014. Effect of Sand Fouled Ballast on Train-Induced Vibration. International Journal of Pavement Engineering Vol.15, No.7, 635-644.

Fontul, S., Furtunato, E., De Chiara, F., Burrinha, R., Baldeiras, M., 2016. Railways Track Characterization Using Ground Penetrating Radar, Procedia engineering, 143, 1193-1200.

Huang, H., Tutumluer, E., 2011. Discrete Element Modeling for Fouled Railroad Ballast. Construction and Building Materials. 25, 3306-3312.

Indraratna, B., Ngo, N.T., Rujikiatkamjorn, C., Vinod, J.S., 2014. Behavior of Fresh and Fouled Railway Ballast Subjected to Direct Shear Testing: Discrete Element Simulation. International Journal of Geomechanics, 14(1): 34-44.

Indraratna B., Su, L.J., Rujikiatkamjorn, C., 2011. A New Parameter for Classification and Evaluation of Railway Ballast Fouling. Canadian Geotechnical Journal 48, 322-326.

Kashani, H.F., Ho, C.L., Hyslip, J.P., 2018. Fouling and Water content Influence on the Ballast Deformation Properties. Construction and Building Materials. 190, 881-895.

Li, D., Hyslip, J., Sussmann, T., Chrismer, S., 2016. Railway Geotechnics. CRC Press Taylor \& Francis Group, 592p, Boca Raton.

Olhoeft, G.R., Selig, E.T., 2002. Ground Penetrating Radar Evaluation of Railway Track Substructure Conditions. Ninth International Conference on Ground Penetrating Radar, Proc. SPIE Vol. 4758, pp. 48-53.

Parsons, R. L., Rahman, A. J., Han, J., \& Glavinich, T. E. (2014). Track Ballast Fouling and Permeability Characterization by Using Resistivity. Transportation Research Record. 2448 (1), 133-141.

Selig, E.T., Waters, 1994. Track Geotechnology and Substructure Management. Thomas Telford, 446p, London.

Shao, W., Bouzerdoum, A., Phung, S.L., Su, L., Indraratna, B., Rujikiatkamjorn, C., 2011. Automatic Classification of GroundPenetrating-Radar Signals for Railway-Ballast Assessment. IEEE Transactions on Geoscience and Remote Sensing Vol.49, No. 10.

Tosti, F., Ciampoli, L.B., Calvi, A., Alani, A.M., Benedetto, A., 2018. An Investigation into the Railway Ballast Dielectric Properties Using Different GPR Antennas and Frequency systems. NDT and E International 93, 131-140.

Yurlov, D., Zarembski, A.M., Okine, N.A., Palese, J.W., Thompson, H., 2019. Probabilistic Approach for Decelopment of Track Geometry Defects as a Function of Ground Penetrating Radar Measurements. Transportation Infrastructure Geotechnology 6, 1-20. 